\title{
Embodied interpretation: Assessing the knowledge produced through a dance-based inquiry
}

\author{
Yukari Seko', and Trish van Katwyk ${ }^{2}$
}

${ }^{1}$ University of Guelph, Ontario, Canada

${ }^{2}$ University of Waterloo, Ontario, Canada
AOTEAROA

NEW ZEALAND SOCIAL WORK 28(4), 54-66.

CORRESPONDENCE TO: Yukari Seko

yukari.seko@gmail.com

\begin{abstract}
INTRODUCTION: Although the field of social work has experienced an exponential increase in the use of arts-based methodology, the way in which knowledge shared through artful presentations is understood by audience members remains understudied. As arts-based inquiry often involves active co-construction of meanings between researchers, participants and audiences, it is crucial for social work researchers to scrutinise the process of meaning making by audience members. In this article, we explore how audience members make sense of research findings presented through improvisational dance and how the provision of information about the dance may influence viewer responses.
\end{abstract}

METHODS: A personal experience with self-injury documented in a creative poem was represented through the performance of improvisational dance pieces and assessed by two groups of viewers, with and without knowledge of the topic of the dances. The viewers were prompted to interpret the dances by reflecting on the feelings, thoughts and perceptions they had while watching the performance. A thematic analysis was conducted to compare and contrast the responses of the two groups

FINDINGS: By comparing the interpretations of informed and uninformed viewers, we suggest that interpretation can be influenced by normative, socially constructed assumptions that hinder empathic and action-inspiring engagement.

CONCLUSION: We conclude the article with a discussion of potential implications for social work research, practice and education.

KEYWORDS: arts-based inquiry, dance-based research, interpretation, knowledge, self-injury

The past two decades have witnessed a burgeoning growth of arts-based creative methods in qualitative research as researchers across the disciplines of humanities, health and social sciences have begun exploring the arts as a means of conducting research and presenting findings. This enthusiasm has encompassed a wide array of art forms, including photography (Pearce \& Coholic, 2013; Wang \& Burris, 1997), video (Brickell \& Garrett, 2015), theatre (White \& Belliveau, 2011) and dance (Blumenfeld-Jones, 1995; Ylönen, 2003).
Social work researchers are among the early adopters of arts-based methods. This methodology is consistent with social work's mission to understand clients' lived experience and to empower underprivileged individuals and communities. Arts are a powerful means for communicating lived experiences "that are either un-securable or much more difficult to secure through other representational forms" (Eisner, 2006, p. 11). Within the field of social work, interest in arts-based research has stemmed 
primarily from a desire for alternative modes of knowledge mobilisation through which researchers can make their findings accessible to front-line practitioners and public audiences. For example, Yi and Zebrack (2010) utilised the method of photovoice (as developed by Wang \& Burris, 1997) to explore the impact of childhood cancer from the perspective of survivors and their families. Furman, Lietz and Langer (2006) employed poetry to represent qualitative data and develop empathy towards their clients.

Although methodological issues regarding the validity, reliability, objectivity and generalisability of arts-based research have been explored by researchers (e.g., Eisner, 2006), scarce attention has been directed to the manner in which researchers present their findings through an art form, and how audience members make sense of these findings. In many arts-based studies to date, final products of research (i.e., artworks) are considered as a natural outcome, or by-product, of research. The nature and value of the meanings communicated are seldom questioned. If arts-based social work research, as Furman et al. (2006) argue, aims to generate "practical wisdom" that can "affect its audience intellectually and emotionally" and "assist the social worker in making decisions in the field" (p. 25), the conditions within which research findings are presented and interpreted by audiences deserve closer scrutiny.

Using improvisational dance as a product of research and a mode of inquiry, this article explores how viewers make sense of artsbased research findings. In particular, we were interested in whether the provision of pre-performance information (i.e., the topic of the dance) would elicit different emotive, cognitive and explanatory responses. In the following commentary, we first discuss the potential impacts of social conditions on audience perception and then report the findings of our study. A personal experience with self-injury documented in a creative poem was interpreted into a performance of improvisational dance pieces by the authors and presented to two groups of viewers, one with and one without knowledge of the dance topic. Viewers were prompted to reflect on the affective, cognitive and explanatory responses they had while watching the dances. A thematic analysis was conducted to compare and contrast the responses of the two groups. We conclude by discussing how socially constructed assumptions may be activated in responding to arts-based research and explore the implications of our findings for social work research and practice.

\section{Meaning making in qualitative arts-based research}

The days when qualitative research was seen as somewhat unscientific and not well supported by evidence are long gone for the most part. Qualitative methods are now widely used in social and health science research and recognised for the ability to offer deep insight into complex human behaviour: to reveal "the meaning of these behaviors from the perspective of the participants themselves, within their own social context" (Cobb \& Forbes, 2002, p. M197). The qualitative turn was, in part, driven by dissatisfaction with analytical limitations of traditional positivist/ objectivist epistemology. Qualitative methodology allows researchers to "dismantle, deconstruct and decolonise traditional ways of doing science" (Denzin, Lincoln, \& Giardina, 2006, p. 770), and embrace alternative ways of knowing that capture the complexity and richness of human experience. The epistemological stance taken by qualitative researchers is at odds with positivist assumption of data as a neutral conveyer of the truth. In the word of Drucker (2011), qualitative inquiry perceives knowledge as co-constructed, situated, or taken, but not simply given as a natural representation of pre-existing fact.

This realisation in turn demands that researchers address how their own 
subjectivities, biases and particularities may be reflected in the knowledge they produce. It is widely recognised that there is an invisible incubation period in qualitative data analysis, during which time researchers immerse themselves in the data to draw meanings out of intellectual chaos (Hunter, Lusardi, Zucker, Jacelon, \& Chandler, 2002). This qualitative meaning making phase demands that researchers critically explore their own contextual grounds for interpretations, creatively decontextualise and re-contextualise data into interpretations, remain sensitive to emergent knowledge and generate legitimate conclusions to be shared with the stakeholders.

Like other forms of qualitative study, arts-based methods require researchers to critically engage in the construction of meanings through repeated reflection, heuristics and artful constructions.

However, within arts-based research, an emphasis is often placed on the processes of "doing" research, rather than on the end products or legitimate conclusions in the traditional sense. Artful representations are expected to create "an open space for dialogue between readers/perceivers and research participants, as well as opening dialogue with researchers and artists" (Finley, 2003, p. 294) wherein all participants can bring together a range of perceptual, emotional and cognitive experiences to co-construct situated understandings of the phenomenon under study. For some scholars, the dynamic and interactive nature of arts-based research indicates the potential to go beyond just representing knowledge. Denzin (2000) argues for the radical potential of arts-based methods to critique the hegemonic nature of conventional knowledge production and produce new ways of knowing. Encouraging researchers to be sensitive and responsive to political issues a local community faces, Denzin (2000) urges researchers to stand against social injustices and take action for the betterment of the community.
To tease out such radical potentials it is crucial to explore the ways in which research findings conveyed in artful representations are interpreted by audience members whose preferences and perceptions may differ considerably from those of researchers. Surprisingly, there is little discussion about how products of arts-based research are perceived and understood by audience members. For O'Donoghue (2009), this lacuna stems largely from arts-based scholars' disinterest in the cultural and aesthetic competencies that audiences exercise when they interpret arts-based research findings. With reference to Bourdieu's theory of aesthetic taste, $\mathrm{O}^{\prime}$ Donoghue contends that arts-based scholars need to recognise more acutely the sociocultural conditions or codes underlying artistic production and perception and critically examine "the classificatory schemes that are activated in artistic perception" (p. 366).

One avenue to improve arts-based research lies in exploring key factors that encourage or discourage active meaning making by audience members. One such factor is the provision of information by researchers. The few studies that do examine the impact of information provision suggest that audience interpretations can be easily manipulated by interpretative guidance or a specific code given by researchers. Glass (2008), in her psychological experiment with spectators of contemporary dance, measured the impact of pre-performance information provision on an audience's interpretative response to a live dance performance. By comparing three groups with specific, generic and no pre-performance information about the dance, she found that participants who attended the specific information sessions were the most likely to interpret the dance in alignment with the ideas provided. Glass (2008) concluded: "It seems that information sessions served to activate a particular scheme that subsequently affected observers' interpreted responses" (p. 119). Jola, Ehrenberg, and Reynolds (2012) reached a similar view in their research on spectators' kinaesthetic and affective 
responses to watching different types of dance. Audience familiarity with the particular dance style had a decisive impact on how the performance was interpreted. Spectators with previous experience of watching ballet expressed a higher level of understanding of the performance than inexperienced spectators.

The notion that provision of information may affect audience perception raises a significant question as to the extent to which researchers should activate codes or interpretative guidance. For O’Donoghue (2009), arts-based researchers have a responsibility to ensure that their presentations contain "a sufficient degree of referential clarity" for multiple and diverse audiences (p. 359), so that their artful work can be productive enough to avoid the risk of misinterpretation. Yet, researchers' desire to direct audience receptions may obstruct open and active meaning making by the audience. As Jola et al. (2012) argue, audience members are active agents, whose experience of artistic performance is socially mediated rather than purely personal. Accordingly, conducting an experimental exploration into the impact of information provision on audience interpretations may provide an opportunity to further understand meaning making processes in arts-based inquiry.

\section{The dance pieces: Integrating our bodies into knowing}

This study involved two sequential dancebased explorations. The initial purpose of our inquiry was to explore the use of improvisational dance to represent data drawn from research on self-injury by one of the researchers. Themes emerging from the first author's previous interviews with people who self-injure (Seko, Kidd, Wiljer, \& McKenzie, 2015) and visual narrative analysis of self-injury photographs online (Seko \& Lewis, 2016) formed the basis for our exploration.

We conceived of dance as a powerful conduit for invoking and presenting the subjective experience of self-injury; a sensitive, stigmatised and under-researched topic (Whisenhunt et al., 2014). The kinaesthetic and affective nature of dance was also perceived to resonate with the physical and sensory aspect of self-injury. Dance is an event and experience that requires the audience to bear direct and immediate witness beyond purely visual or static experience (Glass, 2008). Improvisational dance served three interconnected purposes: as an alternative means for us, the researchers, to physically engage with and know about qualitative data; as a dynamic and embodied medium to communicate our findings to an audience; and as a research tool to assess how the audience identified meanings in arts-based knowledge translation.

During the summer of 2015, we met four times and spent a total of 15 hours in a dance studio to create a collaborative dance inspired by key themes from the first author's research. As neither of us were trained dancers, Janet Johnson, a professional dancer and choreographer, provided us with support to understand our dance vocabularies. With her guidance, we gradually learned how to trust our bodies and overcame initial apprehension. We improvised movements as we proceeded, and reflected by journaling what came to our minds while dancing. After the summer workshop, we met again in December 2015 to develop another collaborative dance piece. This time we drew our inspiration from a poem representing subjective experiences of self-injury, written in 2007 by Gabrielle, the first author's former research collaborator and a poet with long-term experience of self-injury. The poem entitled "i could not read them" (Figure 1) was chosen because it eloquently represented the physical and psychological turmoil of self-injury and was in close alignment with many of the narrative themes identified in the first author's previous research with people who selfinjure (Seko, 2013; Seko \& Lewis, 2016; Seko et al., 2015). 
Prior to the meeting, we had each selected three passages from the poem and we individually improvised solo pieces based on the assigned passages. In the studio, we collaboratively refined our movements with Janet's guidance. Yakari's piece was inspired by the first 12 lines of the poem (Figure 1) featuring quickened heartbeats and emotional turmoil. The solo consisted of fast, repetitive, chest beating with interlaced fingers and a swallowing gesture followed by a slow swaying movement. Swaying arms eventually formed a snake-like shape that swallowed the dancer. Trish choreographed the final six lines of the poem expressing feelings about survival after self-injury. This piece involved repeated cycles of movement that begin with fingers fluttering high in the air in a slow circle, ending with an abrupt slash down with one hand over the opposite arm. The circling stops and the dancer draws her hands over her face, scrutinises her arms and then raises her arms slowly into the air above her, as if she will take off in calm flight. After a four-hour intensive session, our individual pieces were interwoven, video-recorded and edited into a six-minute video clip.
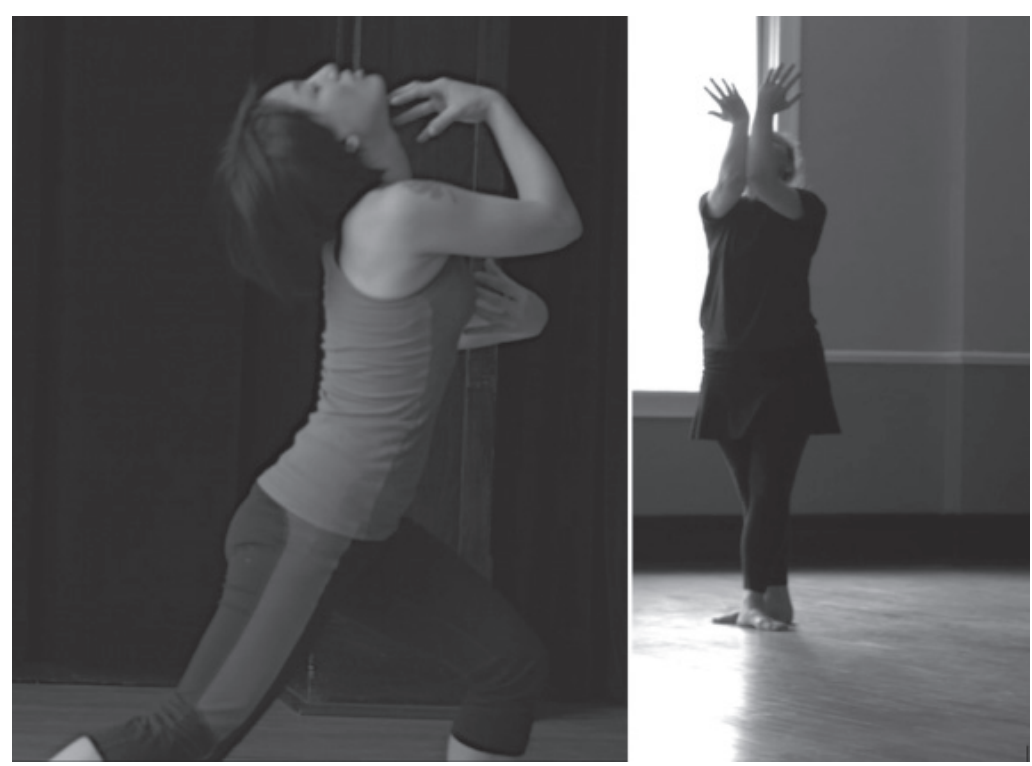

Image 1: Dancing the Poem Photo by Calhoun Breit when $i$ was seventeen my heart beat so fast onetwofiveten beats like that. swallowing charcoal down like water, the grit getting in between my teeth and on my fingers. i wanted to paint the room with

charcoal but, oh god, the letters on the sign were moving. they flew and blurred and twisted like snakes.

there were hands on my clothes, it was too hot. water would do, please. just give me water. my breasts, an ugly word etched on them, felt the cool air. hands tugging my shirt down. the stickiness of monitors being attached. my mother was a blur at my side, she had no eyes. only a mouth that opened like a cavern edged with teeth. my hands shook, my body shook, everything was coming down and there was that salty dirty taste in my mouth. i had vomited until $i$ fell on hands and knees. like a drunk in the gutter $i$ vomited until i was weak and trembling and my mind had gone off to keep another girl company. one who didn't do things like this.

i watched them put a needle through my wrist, eyes crossing, mouth working to try to talk. to

say something. please, don't go away. there was no pain. blood gas. they talked, a distant murmur. please, honey, swallow that charcoal. my mouth was open. i could not close it and there was thick drool on my chin it was dying in reverse. outside there must have been the sun and girls laughing so that their teeth showed. inside i sweated and $i$ could not think. i couldn't think. what were they saying? speak english, please. speak something i can't understand because the words are flying and the shape of $a \mathrm{u}$ is like an $\mathrm{x}$ with a broken limb.

i lay there stupid and shaking, half naked. time had gone to sleep and, oh god, there were scars on my arms that twisted into words i could not read. $i$ was sure if $i$ could read them $i$ would have not woken up. 
In February 2016, we conducted an anonymous open-ended online survey to interrogate audience responses to the improvisational dance pieces. Ethics approval was obtained from the University of Waterloo Research Ethics Board. To examine the perceived impact of pre-given information on audience interpretation, we prepared two questionnaires: one was accompanied with a brief, one-line description of the nature of the dance pieces ("the dance pieces are themed self-injury"), while the other had no such information. All participants were invited to watch the video of the three dance pieces and answer the following questions:

- What feelings did you have as you watched the dance pieces?

- What thoughts did you have as you watched each of the dance pieces?

- What do you think the dance pieces might be saying?

Moules, Field, McCaffrey, and Laing (2014) write of the complexity involved in the act of interpretation. Observers' cognitive, affective and perceptual/explanatory responses come together to determine the meaning made of that which is observed. By asking about thoughts, feelings and explanations, we were not identifying these as distinct processes, but rather as working together to form the complexity inherent in the meaning making process.

Using a convenience sampling method, we sent a recruitment notice with a link to the dance video to a total of 60 people ( 30 for each group) and asked them to take part in the survey. Most of these contacts were based in Canada and were made up primarily of university students in the field of social sciences and humanities, professional artists and healthcare professionals. In order to generate a purposive sample representing a diverse audience group, we approached people with different levels of experience and knowledge about dance and self-injury. About a quarter of the initial contacts were dancers or dance-related professionals, or involved in other forms of performance art, such as theatre. Another quarter of contacts had direct experiences related to self-injury as clinical professionals or caregivers to those who self-injury. The rest of the contacts did not possess particular expertise either in performance art or in self-injury.

Of the 60 invitations that were sent out, 44 were completed with each questionnaire receiving 22 responses. Due to the anonymous design of the online survey, it is not possible to identify which contacts completed the exercise. After completion, all participants were provided with a debriefing letter providing information about the study. The two groups were compared to see if there were any significant differences between cognitive, emotive and explanatory responses. Responses were collaboratively analysed by the authors using thematic content analysis (Saldaña, 2013). This iterative process involved repeated reading and immersion in the data. Both of us first read all responses independently to identify recurrent themes, categories and concepts, while writing analytic memos (Saldaña, 2013) for further reflection. We then met to collaboratively conduct the next rounds of data analysis and discuss emergent themes until agreements were achieved.

\section{Findings}

The dance performance used in this evoked a multitude of affective, cognitive and explanatory responses. Several differences were observed between participants who were informed of the dance topic and those without such knowledge. Emerging themes are described in the following discussion.

\section{Affective reactions}

The respondents in the uninformed group reported a wide range of emotions ranging from negative feelings such as sadness, 
angst and hopelessness to positive feelings such as hopefulness, pleasure and empathy. Two people identified conflicting emotional responses, such as hopelessness and hopefulness, commitment and detachment. These emotional responses were a description of empathy, as they were noted to be directly related to the feelings and stories that the respondents imagined were being expressed.

Eight out of 22 uninformed spectators also described curiosity, uncertainty and the wonderment they felt as they observed the dance performance without knowing the underlying theme. Three respondents worried about whether they were observing and responding "accurately," or in the ways that they were supposed to: "I also felt a bit of anxiety throughout as I could not figure out what the dances were conveying, and I had no-one to ask :-)." For four respondents, the curiosity and wonderment resulted in a great level of engagement, to the extent that they related empathetically to what they perceived the "individual being danced about" was experiencing. By contrast, the lack of information made two respondents disengaged to the point of boredom.

The informed group of respondents also described various feelings they had while watching the dance pieces. The affective responses were predominantly related to negative emotional states, such as helplessness, hopelessness, anger, frustration, fatigue and being overwhelmed. Twelve respondents expressed sadness about the state of isolation they felt was being expressed, and two described feelings of docility or victimhood as they watched the dance story's character. Others described feelings of compassion and sympathy - all suggesting a disheartening and/or unhappy state rather than compassion and sympathy for someone else's joy and achievement; for example: "Empathy for the struggle each dance represented", or "I felt the pain that each dancer was trying to portray".

Fewer respondents than in the uninformed group noted engagement with the performances. One person expressed the feeling of connectedness with the dance piece that seemed to them to convey the more positive message. Curiosity was noted by one informed respondent, and two respondents noted emotional responses to the research medium (dance), stating that they felt moved by certain aspects of performance, and "touched by the Beauty of physical form". No respondent in this group expressed boredom and disengagement from the dance.

\section{Cognitive reactions}

For the uninformed survey respondents, the longing for narrative featured strongly in their responses. Six respondents expressed a desire to find an underlying story to make sense of the dance pieces. With the absence of information that could anchor meanings, the perceptions of the respondents became more subjective and self-conscious: One noted: "My thoughts were less about the actual piece and more about my own inability to understand it. Second guessing myself as viewer".

Without knowing what the dance pieces were about, the uninformed viewers seemed to start to freely explore what each dance represented. Recurrent themes were life struggle, loneliness, turmoil, survival, search for acceptance, self-expression and continuous fight for life. One respondent became intrigued with what dancers were feeling while dancing, rather than what/who the dancer was representing. Four respondents also noted an interest in the dance itself as a mode of narrative expression. They interpreted the dancers' bodily expressions as a message, seeking to understand what story each piece was conveying. Patterns and repetitions in each piece were read as the code or vocabulary that conveyed the narratives. Respondents made statements such as: "I was impressed with the movements the human body is capable of making", and "(I was) fascinated by how some people have such literacy of expression through movement". 
Intriguingly, the desire for a story was also expressed by the informed respondents even though they knew the topic of the dance. Three respondents expressed a need to draw the narrative out and understand what aspect of self-injury each piece would represent. Some considered each piece as representing experiences of different individuals, while others thought each piece symbolised different emotional states of one person engaging in self-injury. Twelve respondents were unsettled by the personal narrative that they thought the dance pieces were evoking, and interpreted the dance as expressing the difficulty of ceasing to self-injure, using words such as "trapped" and "no way out".

In an attempt to read the story behind the dances, the informed viewers tended to draw on existing knowledge about selfinjury. For instance: "Self-injury is isolating and yet the women are looking to connect," or "Self-injury is exhausting and relentless and it seemed overwhelming and I thought people might give up". One person

expressed surprise that the dancers seemed to symbolise self-care, rather than self-harm: "The pieces did not fit my vision on people doing themselves harm". This may reflect a presupposition towards self-injury; the person might be looking for a stereotypical narrative about self-injury in the dances and was surprised at not being able to find such a story. Moreover, two respondents in the informed group mentioned researchers' responsibility to censor expression; they pointed out that one of the dance pieces might be "triggering" because it involves a gesture of slashing on the arm.

\section{Explanations}

As with the affective and cognitive responses, provision of the dance topic influenced how the audience explained the dance pieces. The uninformed respondents explained the pieces as the expression of an existential reflection, where a cyclical and autonomous journey of life was being portrayed. In this journey of life, the respondents understood the movements to be the indicators of fight and struggle, resilience and recovery, with ongoing and forward moving cycles of hopelessness and hope, sadness and joy, entrapment and freedom. One person explicitly mentioned that the dances represented: "Life-cycle, hope, faith, attachments that people might have, in fighting, dreams, victories and losses, peaceful and stress moments, love, different facets of life". Occasionally, the focus turned to the expression of the knowledge, and to the dancer rather than the individual whose story was being danced. One noted: "The stories themselves weren't the focus for me... the way the dancers were processing the stories was the point".

The informed respondents tended to explain the pieces as expressing the turmoil or struggle that people who self-injure are going through. Five made reference to a pathology-informed context where self-injury was portrayed as "addictive or inescapable" related to other mental health issues such as an "eating disorder", a "manic-depressive cycle" or "fomication and delusional parasitosis". Suicide was mentioned by five respondents in this set of explanations, as opposed to the uninformed set of explanations where suicide was not mentioned once. Perceived entrapment remained unresolved for the informed group. The individual for whom the story was being told through dance was understood to be remote, closed-off and profoundly misunderstood: unreachable. No informed viewers thought the dance pieces represented resilience or hope: instead, they perceived the dances to be "representative of an under addressed social issue" or the "issues exist in our society with many people feeling isolated and unable to get help".

\section{Discussion}

The findings of this study indicate that the provision of information, even a oneline description of the dance topic, had considerable impact on how viewers felt and thought about the dance pieces and the 
explanations they developed. We believe that these differences suggest how social work researchers can best present their artsbased research findings in a manner that encourages open and dynamic knowledge co-construction with their audience.

In the present study, the group of viewers who did not know the dance topic tended to share open-ended, holistic and emotive views towards the dance pieces, expressed a strong sense of either engagement or disengagement, and showed a keen desire to understand what was being communicated. Although longing for a story or a plot behind the dances, the uninformed spectators flexibly projected subjective interpretations to the dances and created meanings from their own situated perspective. On the contrary, when the topic was known, socially constructed knowledge was brought to the fore; many informed survey respondents showed a deficit-based response, in which self-injury was conceived as a social and public health issue (like suicide) that isolates people. When knowledge is developed along the lines of power, we come to construct ways of knowing that align with dominant views (Foucault, 1980). In this way, many lives can become misrepresented (Ahmed, 2000). Hence, the provision of the dance topic may have led to the reproduction of a normative, diagnostic interpretation of selfinjury wherein people who self-injure are deemed "victims" of mental illness, or docile and subordinated "patients" with acute risk of suicide.

Of note here is that no participant in the informed group expressed the boredom and disengagement that was expressed by a few uninformed participants - even though no one in this group read hope or resilience in the dances. This indicates that these viewers might have felt morally obliged to temper disinterest and sympathetically respond to another's suffering in ways that resonate with their internalised norms. Any disengagement with the performance might, in this light, appear as morally inappropriate. Although literature implies that a personal moral obligation can mitigate prejudice and stereotyping (Monteith \& Walters, 1998), such normative presuppositions may serve to limit audience interpretations and interfere with their ability to fully explore the lived experience being examined through arts-based inquiry. When interpretation is constrained by the imposition of dominant discourses that activate audience's internalised norms, the knowledge produced by the audience may reflect particular social conditions that hinder empathetic and action-inspiring engagement.

Our experimentation was unique in that neither author was a professionally trained dancer. Existing work that employs dancebased methods has been conducted by dancer-researchers with expertise in dance and choreography (Blumenfeld-Jones, 1995; Ylönen, 2003) or by professional dancers guided by researchers to represent research findings (Boydell, 2011). Use of our non-professional bodies as instruments of discovery evoked anxiety, trepidation and apprehension, akin to the intimidating feelings expressed by Carl Bagley when he performed his data through his non-artist body (Cancienne \& Bagley, 2008). Unlike conventional modalities, where researchers hide in the background and produce "objective" knowledge, our dance-based research compelled us to step outside the safe zone, critically interrogate our location within the study, and expose ourselves to a spotlight which we, as researchers, often place participants under.

Even partnered with Janet, a skilled dancer and choreographer, our decision to perform exposed us to our own vulnerability. As we learned how to collaboratively create knowledge with dance partners/coresearchers, this vulnerability helped to afford an in-depth, embodied understanding of people's experiences with self-injury. We believe social work researchers and practitioners - especially those working with underrepresented populations - would benefit greatly from dance-based inquiry as an embodied way of knowing. 
This study highlights that subjective experience not only influences the artistic expression of knowledge, it also affects the meaning making that occurs when encountering art as knowledge. The subjective experience of self-injury that was being "danced about" was subjectively interpreted, regardless of whether the audience had been informed about the dance topic. This raises the point that subjectivity is marked by the particular experience as well as by the constructed experience; a response to dance contains both what is particular to the observer and is guided by the social constructions that the observer has been immersed in. When the topic is not provided, the response contains the particular experience of the observer as well as social constructions that are not connected to the topic of self-injury, but perhaps to other aspects of the observer experience (i.e., dance as an art form).

We are compelled, with these findings, to consider the responsibility of researchers to "think critically about and address the issues of interpretations in arts-based research" (O'Donoghue, 2009, p. 359). As the present study implies, the more discursively guided artful presentations become, the less curiosity-driven and humanistic the audience response might be. Researchers, in an attempt to avoid their work losing its perceived value, may run the risk of disregarding the vast and rich potential of meaning making in arts-based research. Although the idea to present research findings without clear explanations understandably concerns researchers, who wish to accurately deliver their message, presenting their findings in an open-ended manner can invite audience members into a more flexible, open and situated meaning making beyond the researchers' intentionality. In their review of arts-based education research, Sinner, Leggo, Irwin, Gouzouasis, \& Grauer (2006) deemed openness to be "a cornerstone of strong arts-based research" that "encourages more dynamic knowledge construction in the academy as the significance is not always bound by the researcher" (Sinner et al., 2006, p. 1238). From this perspective, presenting artful research findings with no or minimal codes, or interpretative guidance may stimulate audience responses that inform the inquiry in an unanticipated way. Accordingly, it is thus important for artsbased researchers to acknowledge audiences as active agents of meaning making and create an open space for subjective interpretations and active dialogues.

\section{Implications for social work}

The present study has a number of implications for social work research, practice and education.

In social work's ongoing efforts to become more inclusive and socially just in encounters with a diverse range of individuals and communities, we are challenged to extend our critical awareness about how knowledge is created and mobilised. The relationship between knowledge and power is irrefutably strong, as put forward by a wide range of theorists: cultural critic Michel Foucault (1980), critical educator Paulo Freire (2000), critical theorist Sara Ahmed (2000) and Indigenous linguistic theorist Peter Cole (2002). The ways in which knowledge is created, validated and practiced is very much guided by societal structures that are organised by ruling relations (Smith, 1999). These ruling relations create structures that influence how some individuals and communities are scrutinised and erased at the same time by the state, police and social science research (Tuck \& Yang, 2014). For these communities, research has done harm and is considered with suspicion and caution (Smith, 1999). Alternative methods of research can present a resistance to knowledge practices that have excluded or eradicated human experience.

Social work practice is based in social research; the knowledge we gain through social research is what we use to shape our practices. When knowledge is produced 
in ways that are constricted by a dominant view, the practices that flow out of that knowledge will be become irrelevant to the lives of many of the individuals and communities that social workers encounter. Daley (2010) calls for the development of "liberatory and transformative research practices that recognise and respond to power in the research process" (p. 68). Arts-based research, as a community-based, participatory and qualitative methodology, is able to centre the experience of participants: involve the participants (including researchers) in a "being and doing" of knowledge; and unsettle the power dynamics found in many research encounters. Tuck and Yang (2014) argue:

The pursuit of objectivity, always defined by those in power to protect their power, occludes the intuition of the observerthe sixth sense that could be his or her ethical radar and moral compass...we often turn toward art to give language to the intuitive. Using art to think/feel through theory-to decode power and uncode communities. (p. 814).

When knowledge production includes multiple and diverse expressions of knowledge that explore subjective meaning making, a new space in research is created. In this space, new ways of knowing, being and encountering can occur that transcend the oppressions of a dominant structure.

Recognising that knowledge production at the "audience end" can involve open, curiosity-driven approaches or socially constructed, distancing and victimising approaches benefits social researchers who wish to analyse and represent qualitative data in a manner that stimulates alternative meaning making. To gain greater awareness of how "codes" can determine the way their research may be interpreted, social work researchers may benefit from works in areas such as social semiotics, critical art history, audience studies and postcolonial studies that shed light on the social conditions underlying audience interpretations.
Appreciating the potential impact of pre-determined codes and knowledge structures can be beneficial for social work practitioners, especially those who work with over-scrutinised and/or erased communities and individuals. When practitioners activate dominant codes, moral obligations and internalised norms, their capacity for open engagement, empowering encounter and deep empathy may be diminished (Ashcroft \& Van Katwyk, 2016; Chambon, 1999). As a result, their practice can become oppressive in their problem-focussed understanding, and locked into a generalised narrative that objectifies rather than subjectifies the people they are intending to support. Understanding how their own presentation of issues may serve to maintain dominant, often oppressive discourses may thus stimulate critical self-reflection, a significant skill for social workers.

Our decision to integrate our bodies into data analysis and knowledge representation can have educational implications for social work students. The knowledge (research data) and the conveyer of knowledge (our body) were inextricably intertwined in the present study, enabling us to explore the topic of self-injury in a subjective and embodied way and to question the normally invisible position of researchers. Awareness of the way in which knowledge and power are intertwined may also foster student capacity to critically assess the educational process; to critique the relationship between the knowledge that is being considered in preparation for practice in the social work field and the context of its production.

The present work has limitations. In this study, the dance pieces were performed in neutral clothing and presented without background music. However, improvisational dance is often a multi-sensorial event consisting of many modalities such as music, sound effects, costumes, lighting and stage (Jola et al., 2012). Paying attention to these sensory and emotive stimuli would benefit future research, as these are often used by audience 
as cues to interpret dance performances (Glass, 2008). Also, generalisation of findings is limited as we employed a convenience sampling method and administered the survey anonymously. Future research could use a more rigorous purposive sampling method to generate a sample that represents a diverse population with varying degrees of experience and expertise in dance and the topic of self-injury.

Although our dance-based inquiry promoted engaged interpretations at an individual level, our approach did not invite greater involvement of the audience members throughout the project. There was no space for a collective dialogue among audience members after viewing the dance pieces due to the anonymous design of the survey. It would be beneficial for future research to conduct interviews or focus groups with audience members following the survey and co-investigate how their social conditions and locations might have affected the process of meaning making. Such active dialogue with audience members would resonate with researchers aiming to employ participatory, community-based methods to explore collective knowledge co-construction with research participants.

In a related vein, future research may also benefit from involving people who self-injure in a dance-based exploration, ideally from the inception of the project. This could shed light on the process of multiple meaning making inherent to arts-based research and stimulate active dialogue between researchers, participants, audience and other potential stakeholders. For such a participatory approach, it would be critical for researchers to constantly attend to emergent ethical issues. In the present study, two informed respondents found the gesture of slashing on the arm to be potentially triggering to those who self-injure, while no uninformed participant reported such a concern. This interpretation might be influenced by dominant presupposition that self-injury is contagious and people who self-injure are always prone to visual stimuli. Research design, which considers the dominant codes behind such ethical concerns, may facilitate more open reflection by audience members in the interpretation of arts-based research presentations.

\section{References}

Ahmed, S. (2000). Strange encounters: Embodied others in post-coloniality. Oxon, United Kingdom; New York, NY: Psychology Press; Routledge.

Ashcroft, R., \& Van Katwyk, T. (2016). An examination of the biomedical paradigm: A view of social work. Social Work in Public Health, 31(3), 140-152.

Blumenfeld-Jones, D. S. (1995). Dance as a mode of research representation. Qualitative Inquiry, 1(4), 391-401.

Boydell, Katherine M. (2011). Making sense of collective events: The co-creation of a research-based dance [43 paragraphs]. Forum Qualitative Sozialforschung/Forum: Qualitative Social Research, 12(1), Art. 5. Retrieved from http://nbn-resolving.de/urn:nbn:de:0114-fqs110155.

Brickell, K., \& Garrett, B. (2015). Storytelling domestic violence: Feminist politics of participatory video in Cambodia. ACME: An International E-Journal for Critical Geographies, 14(3), 928-953.

Cancienne, M. B., \& Bagley, C. (2008). Dance as method: The process and product of movement in educational research. In P. Liamputtong \& J. Rumbold (Eds.), Knowing differently: Arts-based and collaborative research methods (pp. 169-186). New York, NY: Nova Science Publishers.

Chambon, A. S. (1999). Foucault's approach: Making the familiar visible. In A. S. Chambon, A. Irving, \& L. Epstein (Eds.), Reading Foucault for social work (pp. 51-81). New York, NY: Columbia University Press.

Cobb, A. K., \& Forbes, S. (2002). Qualitative research what does it have to offer to the gerontologist? The Journals of Gerontology Series A: Biological Sciences and Medical Sciences, 57(4), M197-M202.

Cole, P. (2002). Aboriginalizing methodology: Considering the canoe. International Journal of Qualitative Studies in Education, 15(4), 447-459.

Daley, A. (2010). Reflections on reflexivity and critical reflection as critical research practices. Affilia: Journal of Women and Social Work, 25(1), 68-82.

Denzin, N. K. (2000). Aesthetics and the practices of qualitative inquiry. Qualitative Inquiry, 6(2), 256-265.

Denzin, N. K., Lincoln, Y. S., \& Giardina, M. D. (2006). Disciplining qualitative research. International Journal of Qualitative Studies in Education, 19(6), 769-782.

Drucker, J. (2011). Humanities approaches to graphical display. Digital Humanities Quarterly 5, 1. Retrieved from http://digitalhumanities.org/dhq/vol/5/1/000091/000091.html.

Eisner, E. (2006). Does arts-based research have a future? Inaugural lecture for the first European conference on arts-based research, Belfast, Northern Ireland, June 2005. Studies in Art Education, 48(1), 9-18.

Finley, S. (2003). Arts-based inquiry in QI: Seven years from crisis to guerrilla warfare. Qualitative Inquiry, 9(2), 281-296.

Foucault, M. (1980). Power/knowledge: Selected interviews and other writings, 1972-1977. New York: Pantheon. 
Freire, P. (2000). Pedagogy of the oppressed: $30^{\text {th }}$ anniversary edition. New York, NY: Bloomsbury Academic.

Furman, R., Lietz, C., \& Langer, C. L. (2006). The research poem in international social work: Innovations in qualitative methodology. International Journal of Qualitative Methods, 5(3), 24-34.

Glass, R. (2008). Observer response to contemporary dance. In R. Grove, C. Stevens, \& S. McKechnie (Eds.), Thinking in four dimensions: Creativity and cognition in contemporary dance (pp. 107-121). Carlton, VIC: Melbourne University Press.

Hunter, A., Lusardi, P., Zucker, D., Jacelon, C., \& Chandler, G. (2002). Making meaning: The creative component in qualitative research. Qualitative Health Research, 12(3), 388-398.

Jola, C., Ehrenberg, S., \& Reynolds, D. (2012). The experience of watching dance: Phenomenologicalneuroscience duets. Phenomenology and The Cognitive Sciences, 11(1), 17-37.

Monteith, M. J., \& Walters, G. L. (1998). Egalitarianism, moral obligation, and prejudice-related personal standards. Personality and Social Psychology Bulletin, 24(2), 186-199.

Moules, N. J., Field, J. C., McCaffrey, G. P., Laing, C. M. (2014). Conducting hermeneutic research: The address of the topic. Journal of Applied Hermeneutics, 7, 1-13.

O'Donoghue, D. (2009). Are we asking the wrong questions in arts-based research? Studies in Art Education, 50(4), 352-368.

Pearce, K., \&Coholic, D. (2013). A photovoice exploration of the lived experiences of a small group of aboriginal adolescent girls living away from their home communities. Pimatisiwin: A Journal of Aboriginal \& Indigenous Community Health, 11(1), 113-124.

Saldaña, J. (2013). The coding manual for qualitative researchers. London, United Kingdom: Sage.

Seko, Y. (2013). Picturesque wounds: A multimodal analysis of self-injury photographs on Flickr. Forum Qualitative Sozialforschung/Forum: Qualitative Social Research, 14(2). Retrieved from http://nbn-resolving.de/ urn:nbn:de:0114-fqs1302229

Seko, Y., Kidd, S. A., Wiljer, D., \& McKenzie, K. J. (2015). On the creative edge exploring motivations for creating non-suicidal self-injury content online. Qualitative Health Research, 25(10), 1334-1346.

Seko, Y., \& Lewis, S. P. (2016). The self-harmed, visualized and reblogged: (Re)making of selfinjury narratives on Tumblr, New Media \& Society. doi:10.1177/1461444816660783

Sinner, A., Leggo, C., Irwin, R. L., Gouzouasis, P., \& Grauer, K. (2006). Arts-based educational research dissertations: Reviewing the practices of new scholars. Canadian Journal of Education, 29(4), 1223-1270.

Smith, L. T. (1999). Decolonizing methodologies: Research and indigenous peoples. London, United Kingdom; New York, NY: Zed Books.

Tuck, E., \& Yang, K. W. (2014). Unbecoming claims pedagogies of refusal in qualitative research. Qualitative Inquiry, 20(6), 811-818.

Wang, C., \& Burris, M. A. (1997). Photovoice: Concept, methodology, and use for participatory needs assessment. Health Education \& Behavior, 24(3), 369-387.
Whisenhunt, J. L., Chang, C. Y., Flowers, L. R., Brack, G. L., O'Hara, C., \& Raines, T. C. (2014). Working with clients who self-injure: A grounded theory approach. Journal of Counseling \& Development, 92(4), 387-397.

White, V., \& Belliveau, G. (2011). Multiple perspectives, loyalties and identities: Exploring intrapersonal spaces through research-based theatre. International Journal of Qualitative Studies in Education, 24(2), 227-238.

Yi, J., \& Zebrack, B. (2010). Self-portraits of families with young adult cancer survivors: Using photovoice. Journal of Psychosocial Oncology, 28(3), 219-243.

Ylönen, M. E. (2003). Bodily flashes of dancing women: Dance as a method of inquiry. Qualitative Inquiry, 9(4), 554-568. 